\title{
Estimation of Energy Spectrum and Energy Deposition of Photons Emitted from Brachytherapy ${ }^{125}$ I Seed
}

\author{
Amal Yousif Al Yasiri ${ }^{*}$ and Hayder Fadhl Abed ${ }^{2}$ \\ 1Department of Basic Sciences, College of Dentistry - University of Baghdad Iraq; aa9x8@mail.missouri.edu \\ 2Karbala Technical Institute -Al-Furat Al-Awsat Technical University Iraq; inkr.hdr1@atu.edu.iq
}

\begin{abstract}
Objective: The objective of the current study was to estimate the energy spectrum and energy deposition of the photons emitted from ${ }^{125}$ I seed model 6711 with and without the presence of titanium capsule using Monte-Carlo N-Particle code (MCNP) in order to investigate whether the titanium capsule attenuates photons and how much would be the attenuation. Materials and Methods: Two models were built and simulated using MCNPX code, in the first model, the simulation was performed assuming the geometry of ${ }^{125}$ I seed provided by the manufacturers. Whereas in the second model, the simulation was performed assuming that ${ }^{125}$ I seed without titanium encapsulation. For both models, the energy and energy deposition of the photons were estimated. Results: MCNPX computations showed that the energy spectrum released from ${ }^{125}$ I seed with the presence of the capsule was lower than that released without the presence of the capsule for all energies in the spectrum by approximately $19 \%$. Further, the energy deposition computed with the presence of titanium capsule was lower than that computed without the presence of titanium capsule by nearly $31 \%$. Conclusion: The titanium capsule has an impact on the energy spectrum as well as energy deposition of the photons emitted by ${ }^{125}$ I seed. According to the MCNPX results, titanium capsule attenuates the energy and energy deposition of the radiation emerged from the seed by nearly $19 \%$ and $31 \%$ respectively.
\end{abstract}

Keywords: Brachytherapy, Energy Deposition, Energy Spectrum, 125I Seed, Model 6711, MCNP

\section{Introduction}

Interstitial brachytherapy using permanent radioactive implants is a common choice for most patients with prostate cancer- $\stackrel{1-3}{ }$. Iodine-125 $\left({ }^{125} \mathrm{I}\right)$ has been widely used for permanent implants in prostate brachytherapy ${ }^{2}, \mathbf{4 - 6}$. The advantages of ${ }^{125} \mathrm{I}$ over gold-198 and radon are; its lower photon energy results in requiring less shielding 2,5 , and its longer half-life (59.4 days) makes it an appropriate for storage. However, the dosimetry of ${ }^{125} \mathrm{I}$ is more complicated than the conventional interstitial sources ${ }^{5}$.

Iodine- 125 seeds are classified according to the design of sealed radioactive sources ${ }^{7}$. Three commercial models of ${ }^{125} \mathrm{I}$ seed have been manufactured, which are 6701, 6702, and 6711. These models are similar in encapsulation and size but different in the design of active source ${ }^{5}$. In the current study, model 6711 has been selected to estimate the energy spectrum and energy deposition of the photons emitted from ${ }^{125} \mathrm{I}$ seed. The encapsulation of this seed composed of titanium tube of $0.05 \mathrm{~mm}$ thickness welded at both ends to shape a cylindrical capsule which has outer diameter of $0.8 \mathrm{~mm}$ and length of $4.5 \mathrm{~mm}^{5,7}$. Model 6711 seed contains a silver rod ( $3 \mathrm{~mm}$ length) where ${ }^{125} \mathrm{I}$ is adsorbed on its surface ${ }^{7-8}$. Figure 1 shows the schematic diagram of ${ }^{125}$ I seed model 6711.

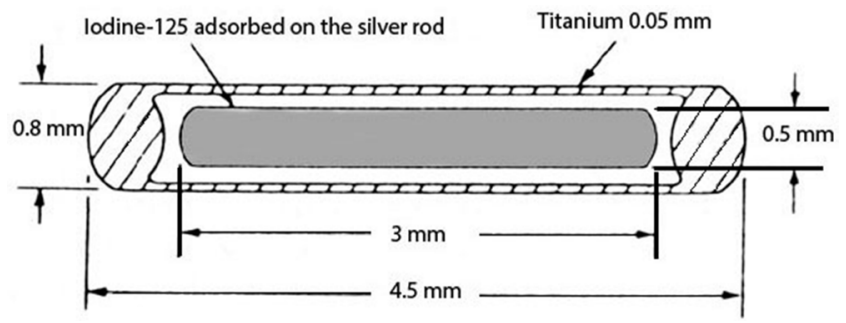

Figure 1. Schematic diagram of ${ }^{125} \mathrm{I}$ seed model 6711 . The geometry of this figure is not drawn to scale. The information of this figure is derived from references $5,2,14$. 
Iodine- 125 is one of the man-made radioisotopes produced in the nuclear reactor. " 125 I is produced mainly in a neutron activation process, through xenon-124 $\left({ }^{124} \mathrm{Xe}\right)$ gas target to give rise to ${ }^{125} \mathrm{Xe}$. In turn, ${ }^{125} \mathrm{Xe}$ decays into ${ }^{125} \mathrm{I}$ by electron-capture (EC) transition. The half-life of the ${ }^{125} \mathrm{Xe}$ is 16.9 hours. ${ }^{125} \mathrm{I}$ also decays by EC into an excited state ${ }^{125} \mathrm{Te}^{\star}$, producing the maximum photon energy of $35.5 \mathrm{keV}$ by gamma decay ( $6.7 \%$ of the time) See Figure 2. In addition, the transition leads to characteristic $\mathrm{x}$-rays of energy between 27.2 to $31.7 \mathrm{keV}$ (K-shells) as a result of internal conversion (93.3\%). Also, very low-energy $\mathrm{x}$-ray of $3.8 \mathrm{keV}$ is also possible (15\%) but in practice very low energy photons are attenuated within the source capsule" 9 .The production and decay processes of ${ }^{125} \mathrm{I}$ are shown in the equations below ${ }^{9}$.

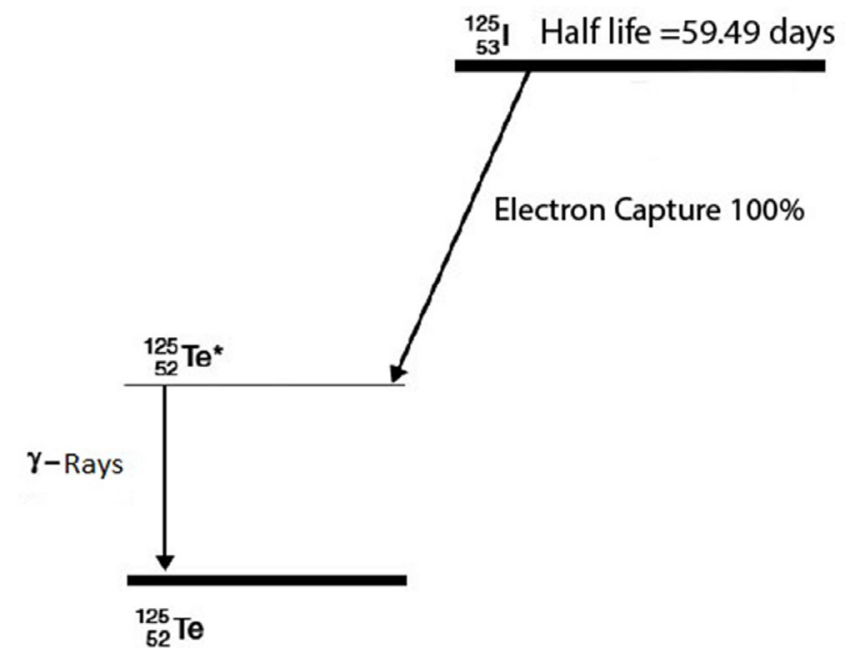

Figure 2. Decay scheme of ${ }^{125}$ I. It was drawn according to the information from (6).

$$
\begin{aligned}
& { }^{124} \mathrm{Xe}+{ }^{1} \mathrm{n} \longrightarrow{ }^{125} \mathrm{Xe}+\gamma \\
& { }^{125} \mathrm{Xe}+{ }^{-e} \longrightarrow{ }^{125} \mathrm{I}+\boldsymbol{v} \\
& { }^{125} \mathrm{I}+\mathrm{e} \longrightarrow{ }^{125} \mathrm{Te}^{\star}+\gamma(6.7 \%)+\mathrm{X} \text {-rays }(93.3 \%)
\end{aligned}
$$

Iodine- 125 emits gamma and $\mathrm{x}$-photons with spectrum of energies ranges from 3.3 to $35.5 \mathrm{Kev}^{10}$. In ${ }^{125} \mathrm{I}$ seed used in brachytherapy, the radioactive source of ${ }^{125} \mathrm{I}$ is encapsulated by titanium material with a thickness of $0.05 \mathrm{~mm}^{5,7}$, and so the photons released from ${ }^{125}$ I source must pass through the titanium material before reaching the tissue. The current study was designed to estimate the energy spectrum and energy deposition of the photons emitted from ${ }^{125}$ I source with and without the presence of titanium capsule using Monte-Carlo N- Particle code (MCNP) in order to investigate whether the titanium capsule attenuates photons.

\section{Materials and Methods}

\subsection{Source Description}

Iodine-125 seed model 6711 was used for MCNP simulations in the current study. Simple geometrical model of this seed was built according to the geometry of the seed provided by the manufacturers (See Figure 1) in which the design consists of a cylindrical core made of silver that has a length of $0.3 \mathrm{~cm}$ and diameter of $0.05 \mathrm{~cm}$, onto which very thin layer of ${ }^{125} \mathrm{I}$ has been uniformly adsorbed. The silver core is encapsulated within a cylindrical titanium housing of diameter $0.08 \mathrm{~cm}$, length $0.45 \mathrm{~cm}$, and thickness $0.005 \mathrm{~cm}$, with rounded titanium welds at each end. The space between the silver core and titanium capsule assumed to be filled with air. Physical properties of the materials used in ${ }^{125} \mathrm{I}$ seed are tabulated in Table 1.

Table1. Physical properties of ${ }^{125} \mathrm{I}$ seed model 6711 components $^{2}$

\begin{tabular}{|l|l|l|l|}
\hline Material & $\begin{array}{l}\text { Mass Density } \\
\left(\mathrm{g} / \mathrm{cm}^{3}\right)\end{array}$ & $\begin{array}{l}\text { Atomic } \\
\text { Number }\end{array}$ & Physical State \\
\hline Iodine $\left({ }^{125} \mathrm{I}\right)$ & 4.933 & 53 & Sold \\
\hline Silver $(\mathrm{Ag})$ & 10.49 & 47 & Sold \\
\hline Titanium $(\mathrm{Ti})$ & 4.5 & 22 & Sold \\
\hline Air & 0.00129 & 7.62 & Gas \\
\hline
\end{tabular}

\subsection{MCNP Simulation}

MCNP simulation is a robust and beneficial technique in brachytherapy measurements. Currently, there are several versions of MCNP code exist; in the present study, MCNPX code, version 2.7.0 was utilized to estimate the energy spectrum and energy deposition of the photons emitted from brachytherapy ${ }^{125}$ I seed used for prostate cancer treatment.

Herein, two models were simulated using MCNPX, the first model was implemented by assuming the geometry of ${ }^{125} \mathrm{I}$ seed as shown in Figure 1 with adding an imaginary air sphere with radius of $10 \mathrm{~cm}$ surrounds titanium capsule. Whereas the second model was performed by assuming that ${ }^{125} \mathrm{I}$ seed without titanium encapsulation (i.e. removing titanium encapsulation from ${ }^{125} \mathrm{I}$ seed), and also assuming an imaginary air sphere with radius of $10 \mathrm{~cm}$ surrounds silver cylinder. For both models, the energy spectrum and energy deposition of the photons were estimated at the surface of air sphere in order to investigate the impact of the encapsulation on the energy 
spectrum and energy deposition of photons emitted from ${ }^{125}$ I source and how much would attenuate the photons. As it was mentioned earlier, ${ }^{125} \mathrm{I}$ emits photons of gamma and $\mathrm{x}$-rays with a spectrum of energies ranges from 3.3 to $35.5 \mathrm{KeV}$, the very low-energy photons are attenuated within the capsule. Therefore, only photons with energies ranging from $27-35.5 \mathrm{KeV}$ were included in the present MCNPX simulation. The photon energies used for the current simulation are listed in Table 2.

Table 2. The spectrum of ${ }^{125} \mathrm{I}$ energies included in MCNP simulation

\begin{tabular}{|l|l|}
\hline Energy (MEV) & Weight (\%) \\
\hline 0.0272 & 17.9245 \\
\hline 0.0275 & 33.4681 \\
\hline 0.0310 & 11.6352 \\
\hline 0.0355 & 30.0090 \\
\hline
\end{tabular}

In this current study, the source was supposed to have cylindrical shape with a radius similar to that of the silver rod because radioactive ${ }^{125} \mathrm{I}$ is adsorbed homogenously on the surface of cylindrical silver rod. Computationally MCNP F1 and F6 tallies were utilized to estimate the energy spectrum and energy deposition of the photons that are emitted by the ${ }^{125}$ I seed.

\section{Results and Discussions}

MCNP code has many advantages that makes it suitable for use in brachytherapy field, for instance, it can transport the electrons and photons in the range of energy from $1 \mathrm{KeV}-100 \mathrm{MeV}$, which is a very important feature because brachytherapy uses low energy sources. In addition, this code is able to model precisely the complex geometry of the sources used in brachyther$\mathrm{apy}^{2}$. Further, MCNP computations provide precise results because they simulate each physical process taking place inside the target. The number of simulated particles must be extremely large for the results to be statistically reliable ${ }^{11}$.

In the current work, two models were simulated using MCNPX code, in the first model, the MCNPX simulation was performed assuming the geometry of ${ }^{125} \mathrm{I}$ seed shown in Figure 1. Whereas in the second model, the simulation was performed assuming that ${ }^{125} \mathrm{I}$ seed without titanium encapsulation (i.e. removing titanium encapsulation from the seed). For both models, the energy and energy deposition of the photons were estimated. The simulations of two models and their results are depicted in the next sections.

\subsection{MCNPX Simulation to Estimate Energy Spectrum for Both Models of 125I Seed}

F1 Tally was performed to estimate the energy spectrum of the photons emerged from ${ }^{125}$ I source for two models (with and without titanium capsule). F1 Tally is beneficial for verifying conservation of the number of particles and conservation of energy ${ }^{12}$. It is measured in unit of $\mathrm{MeV}^{13}$. The energy spectra for both models were measured at the surface of the imaginary air sphere with radius of $10 \mathrm{~cm}$ that surrounds the ${ }^{125}$ I seed.

The simulation results to estimate energy spectrum of the photons emitted from ${ }^{125}$ I seed for both models are shown in Figure 3 which represents a comparison between the energy spectra computed for these models. As seen from this figure, the energy spectrum released from ${ }^{125} \mathrm{I}$ seed with presence of the capsule was lower than that released without presence of the capsule for all energies in the spectrum. The data clearly shows that the titanium has an effect on energy spectrum emitted by ${ }^{125} \mathrm{I}$ source; it attenuates the energy spectrum by approximately $19 \%$ in comparison with energy spectrum released from ${ }^{125} \mathrm{I}$ source and computed without titanium capsule.

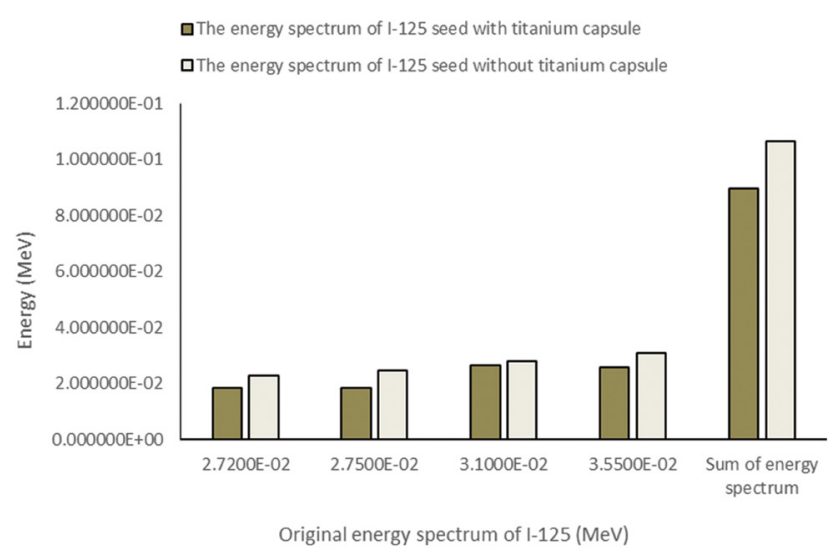

Figure 3. Comparison between the energy spectra of ${ }^{125} \mathrm{I}$ seed of two models (with and without titanium capsule). 


\subsection{MCNPX Simulation to Estimate Energy Deposition for Both Models of 125I Seed}

F6 Tally was performed to estimate the energy deposition of the photons emerged from the ${ }^{125}$ I source with and without passing through the titanium capsule. F6 tally is used to estimate energy deposition averaged over a cell and is measured in unit of $\mathrm{MeV} / \mathrm{g}^{13}$. The energy deposition was measured at the surface of the imaginary air sphere with radius of $10 \mathrm{~cm}$ that surrounds the ${ }^{125}$ I source.

The data was acquired to estimate energy deposition of ${ }^{125}$ I seed with and without the presence of titanium capsule are plotted in Figure 4 which represents a comparison between the data of both models. It can be seen from this figure that the energy deposition computed with the presence of titanium capsule was less than that computed without presence of titanium capsule by nearly $31 \%$. This result confirms that the titanium causes an attenuation to the radiation emitted from ${ }^{125}$ I source.

The results of the current study indicated that the energy spectrum of the photons emitted by the ${ }^{125} \mathrm{I}$ source is attenuated by the titanium capsule as well as through the space between the source and the encapsulation. The present result could have a benefit in dosimetry and dose calculation and can be employed to calculate the absorbed dose accurately by taking in to account the attenuation of radiation by titanium capsule. However, more studies need to be performed to confirm the present results.

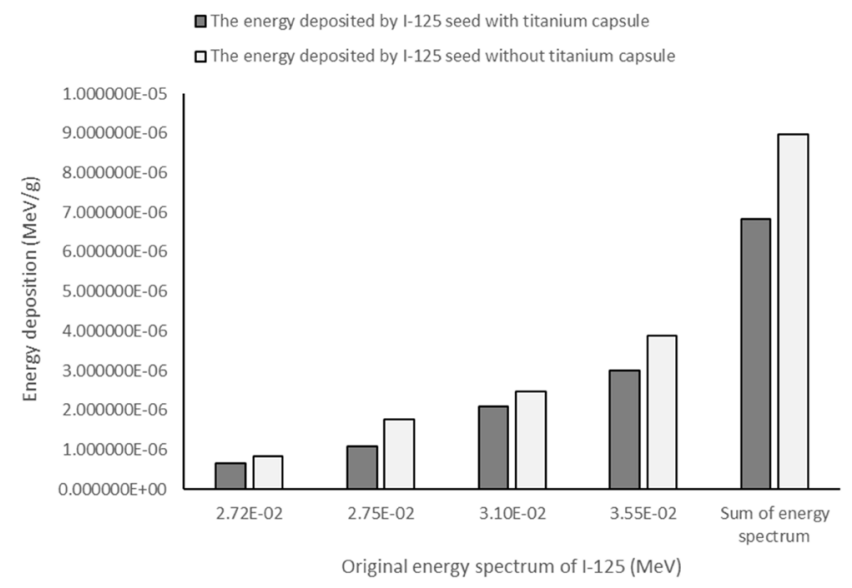

Figure 3. Comparison between the energy deposition of ${ }^{125}$ I seed of two models (with and without titanium capsule).

\section{Conclusion}

The titanium capsule has an impact on the energy spectrum as well as energy deposition of the photons emitted by ${ }^{125}$ I source. According to the current MCNPX results, titanium capsule attenuates the energy and energy deposition of the photons emerged from the seed by nearly $19 \%$ and $31 \%$ respectively. The percentage of attenuation occurred due to the titanium capsule should take into consideration when calculating the absorbed dose during the brachytherapy treatment using ${ }^{125}$ I seeds.

\section{Acknowledgements}

This study was carried out at Nuclear Sciences and Engineering Institute-University of Missouri-USA.

\section{Author Disclosure Statement}

The authors declare that have no conflicts of interest.

\section{References}

1. Woolsey J, Miller N, Theodorescu D. Permanent interstitial brachytherapy for prostate cancer: a current review. World Journal of Urology. 2003; 21(4):209-19. Crossref. PMid:12920559.

2. Baghani HR, Lohrabian V, Aghamiri MR, Robatjazi M. Monte Carlo Determination of Dosimetric Parameters of a New 125 I Brachytherapy Source According to AAPM TG-43 (U1) Protocol. Archives of Iranian Medicine. 2016; 19(3):186-91. PMid:26923890.

3. Meigooni AS, Meli JA, Nath R. Interseed effects on dose for 125I brachytherapy implants. Medical Physics. 1992; 19(2):385-90. Crossref. PMid:1584137.

4. Williams BV, Horton J, Lawyer A, Chapman J. Loading technique comparison in permanent 125 I prostate implants. Medical Dosimetry. 1999; 24(4):273-7. Crossref.

5. Khan FM, Gibbons JP. Khan's the physics of radiation therapy. 5th Edition. Lippincott Williams \& Wilkins. 2014; p. 1-624.

6. Feher A, Rostelato ME, Zeituni CA, Calvo WA, Somessari SL, Moura JA, Moura ES, Souza CD, Rela PR. Leakage test evaluation used for qualification of iodine-125 seeds sealing. Nukleonika. 2011; 56(4):375-9.

7. Zeituni CA, Souza CD, Moura ES, Sakuraba RK, Rostelato MEC, Feher A, Moura JA, Somessari S, Costa OL. Theoretical, manufacturing and clinical application aspects of a prostate brachytherapy I-125 source in Brazil. Brachytherapy. 2012; p. 1-19. 
8. Nath R, Anderson LL, Luxton G, Weaver KA, Williamson JF, Meigooni AS. Dosimetry of interstitial brachytherapy sources: recommendations of the AAPM Radiation Therapy Committee Task Group No. 43. American Association of Physicists in Medicine. Medical Physics. 1995; 22(2):20934. Crossref. PMid:7565352.

9. Hoppe R, Phillips TL, Roach M. Leibel and Phillips Textbook of Radiation Oncology-E-Book: Expert Consult. Elsevier Health Sciences. 2010; p. 1-1664. PMid:21181176.

10. Mourao AP, Campos TPRD. Radiodosimetric considerations on ocular brachytherapy with iodine-125 and ruthenium/rhodium-106. Radiologia Brasileira. 2009; 42(1):43-8. Crossref.
11. Badragan I, Sterian P. Space phase characteristics of a typical i-125 brachy seed, Modelled by Monte Carlo techniques. UPB Scientific Bulletin, Series A: Applied Mathematics and Physics. 2009; 71(4):81-8.

12. Shultis JK, Faw RE. An MCNP primer. 2011.

13. Pelowitz DB. MCNPX user's manual. Version 2.7.0. 2011; p. 1-645.

14. Loftus T. Exposure standardization of iodine-125 seeds used for brachytherapy. Journal of Research of the National Bureau of Standards. 1984; 89(4):295-303. Crossref. 